\title{
Networking in the Time of COVID
}

\author{
Jacqueline Militello (1)
}

check for

updates

Citation: Militello, Jacqueline. 2021. Networking in the Time of COVID. Languages 6: 92. https://doi.org/ 10.3390/languages6020092

Academic Editors: Anne Bannink and Jet Van Dam

Received: 29 January 2021

Accepted: 13 May 2021

Published: 20 May 2021

Publisher's Note: MDPI stays neutral with regard to jurisdictional claims in published maps and institutional affiliations.

Copyright: (C) 2021 by the author. Licensee MDPI, Basel, Switzerland. This article is an open access article distributed under the terms and conditions of the Creative Commons Attribution (CC BY) license (https:/ / creativecommons.org/licenses/by/ $4.0 /)$.
School of English, University of Hong Kong, Hong Kong; jackiem@hku.hk; Tel.: +852-5507-1183

\begin{abstract}
This study examines how during COVID professionals in the financial sector in Hong Kong experienced adaptations to previous ways of networking and what the material outcomes were. Becoming acquainted traditionally relies heavily on face-to-face interaction to advance and cement feelings of trust that eventually lead to successfully concluded transactions. Using linguistic ethnography, I interviewed 36 professionals about networking during COVID. For all three aspects of networking (creating, cultivating, and utilizing relationships for attaining professional goals), participants indicated significant changes as embodied co-present interactions all but ceased and were replaced by computer-mediated communication, including video platforms such as Zoom. Many, but not all, participants indicated that they had made either no new, or a greatly decreased number of new professional acquaintances, compared to pre-COVID times. The cues that would be present in face-to-face interaction were largely viewed as essential for establishing trust in deepening relationships and achieving professional goals such as concluding transactions. There were some compensatory affordances such as more 'objective' evaluations and equalization for those in more peripheral geographic locations. The material outcomes were that, for most, new relationships were significantly handicapped, resulting in networks in a state of stasis, a situation that privileged extant connections and those with strong professional networks.
\end{abstract}

Keywords: professional discourse; computer-mediated communication; networking; embodied co-presence; trust; acquaintancing; Zoom; COVID

\section{Introduction}

Becoming acquainted with someone new is largely seen as a linguistic endeavor (Maynard and Zimmerman 1984; Svennevig 1999; Usami 2006; Silverstein 2004; Haugh and Carbaugh 2015). In the past, for business, this has been mediated through text on platforms such as LinkedIn or by email; in spoken communication through telephone calls; or through face-to-face embodied interaction such as meetings or conferences. Deepening the acquaintance and realizing a professional relationship, however, have seemed to require face-to-face meetings. COVID has halted many of these physically co-present interactions as governments have proclaimed lockdowns, requiring nonessential workers to remain home. Even as government-mandated lockdowns have eased, many companies have extended remote working arrangements (Verlaine 2020; Bray 2020; Greve 2020) and individuals have been reluctant to meet in person (Blakely 2020; Noonan et al. 2020). Different places have experienced different restrictions at different times throughout the pandemic, but many professionals globally have been faced with similar predicaments surrounding the separation of bodies (Adami et al. 2020), including creating, cultivating, and utilizing new business contacts. Past ways of working one's way up from stranger to acquaintance to trusted collaborator, employee, or partner that relied on rapport-building no longer remain as pre-COVID opportunities for socially serendipitous encounters such as afterwork happy hours, coffee breaks at conferences, and intra-industry networking events have disappeared. It stands to reason, then, that relationship establishment and building have been attempted in novel ways. This study examines impacts on professional networking practices in Hong Kong, an important financial hub, which ranks fourth in the world for competitiveness based on the global financial centres index (Wardle and Mainelli 2021) 
with particular strengths in asset management, capital markets, and banking (Hong Kong Monetary Authority 2021).

Building upon past areas of research and using data from semi-structured interviews, this paper investigates the following global questions. How do recent networking practices and patterns for participants in finance in Hong Kong compare to those found in preCOVID times? How have outcomes for various business goals and areas, including highstakes endeavors, such as financing new companies, forging new business collaborations, and securing employment, been altered by new communicative patterns? Are we largely seeing a development of the same networks that we would have had in pre-COVID times?

This paper proceeds as follows. First, relevant research on networking and modalities will be introduced (Section 2) and methodology and data collection explained (Section 3). Then the data will be presented and analyzed (Section 4) with respect to the impact of COVID on communication and social relations for networking through three phases: meeting new contacts (creating); deepening relationships (cultivating); and employing them for attaining professional goals (utilizing). The paper ends with a discussion of the results and wider issues (Sections 5 and 6).

\section{Relevant Research on Networking and Modalities}

\subsection{Defining Networking}

Business connections, or people who know each other professionally, constitute networks, a form of 'social capital' that can be converted to other forms, including economic capital (Bourdieu 1977, 1986). Those with extensive professional networks have unsurprisingly been shown to have better employment outcomes (Lin 1999; Adler and Kwon 2002; Wolff and Moser 2009; Batistic and Tymon 2017). Business connections are formed by networking, defined as 'a form of goal-directed behavior, both inside and outside of an organization, focused on creating, cultivating, and utilizing interpersonal relationships' (Gibson et al. 2014, p. 150). It encompasses different stages of relationship building and goal orientation, including career advancement and achieving organizational objectives (ibid). Moving along the relationship continuum from creating to cultivating to utilizing, or from stranger to approved collaborator, depends on establishing trust. This begs the question of how trust is warranted and how it is discursively accomplished (Candlin and Crichton 2013, p. 2). In interaction people are placed in positions to employ or evaluate communicative styles that index character or ability that, in turn, result in furthering (or not) the acquaintance or pursuing (or not) some form of business collaboration. In communication studies this relates to warranting, 'the perceived legitimacy and validity of information about another person that one may receive or observe online' (Walther and Lee 2014). Until now, warranting has required in-person meetings at a later point in the relationship building process. COVID, however, has required the separation of bodies, necessitating the development of new practices (Adami et al. 2020), such as increased computer mediated communication (CMC) in relationship building (Jang and Choi 2020; Piller et al. 2020).

\subsection{Networking Activities: Rapport Building and Social Serendipity}

Two iconic network creating and cultivating activities are (1) contact-creating largescale networking events such as alumni gatherings, office parties, and conferences and (2) relationship building 'getting drinks at a bar'. For the creation stage social serendipity, the making of new, potentially beneficial acquaintances not encountered in the course of normal business activity, is valued and is considered to be relatively high at largescale networking events where mingling occurs. Social serendipity and serendipity more generally have been theorized in other fields such as management, communication, and computer studies (Olshannikova et al. 2020). Björneborn (2017) has suggested three broad affordances of serendipity: (1) diversifiability, being able to encounter diverse contents; (2) traversability, mobility to explore; and (3) sensoriability, being able to be perceived by the senses. These are easily observable in face-to-face professional networking with 
the array of unknown faces from different organizations and industries and in different professional roles; the agentive movement ('mingling'); and the embodied encounters with others including handshakes, speech, and observing aspects of their physical appearance. After-work drinks, part of the network cultivating process, can be examined through the lens of activity type: it is a socially constructed, 'culturally recognized activity' with constraints on allowable contributions and setting (Levinson 1979, p. 368). Past studies of acquaintancing interactions have shown a recognizable activity type featuring reciprocal disclosure of personal information (Maynard and Zimmerman 1984; Svennevig 1999; Usami 2006; Silverstein 2004; Haugh and Carbaugh 2015). Such disclosures (if appropriate and well-received) are viewed as one of the contributing mechanisms for increasing rapport, a friendly easiness to a relationship that facilitates the smooth flow of communication (Tannen 1984), thus deepening ties.

\subsection{Off- and Online Modalities}

The comparative suitability of various modalities for creating a sense of intimacy, closeness, or presence has been widely debated. Long before computer mediated communication (CMC) became a possibility, certain historic modalities were held to be more personal and revealing of the sender than others, e.g., handwritten letters over typewritten ones (Dahlheim 2016). Likewise, handwritten comments on student papers were viewed as more personal and evaluated more positively ('engaging', 'friendly', 'accessible') compared to typewritten comments (Morgan and Toledo 2006). With the advent of CMC, comparisons began to be made between new modalities (often chat or email) and face-to-face interaction, with face-to-face viewed as the gold standard. In communication studies one of the early theories was that CMC interactions had negative outcomes in terms of intimacy, efficiency, and trustworthiness due to the absence of nonverbal cues (such as gestures, facial expression, intonation) that are available in embodied co-present interactions: i.e., the 'cues filtered out' theory (Culnan and Markus 1987). These findings were later contradicted by Walther et al. (1994), who showed that with accumulated time and anticipated future interaction, despite the absence of these cues, CMC could be evaluated on a par with face-to-face interaction. Their findings have been supported by later studies on online education, e.g., in a meta-analysis of studies on online learning that found that longer duration increased feelings of social presence and positive affect, suggesting that a 'cues filtered out' theory, where face-to-face communication is compared to CMC in short time frames, is overly simplistic, and that time can lead to rich social relationships (Richardson et al. 2017). Online dating studies, too, have shown that people who interact using CMC adopt new means for forming impressions used for warranting, such as email addresses, homepages, internet search, and reply time (Ellison et al. 2006).

Still, in sociolinguistics, nonverbal and paralinguistic cues have been studied and theorized as integral aspects of the meaning making process (Goffman 1959; Gumperz 1982; Bucholtz and Hall 2016). A more recent study that used multimodal interaction analysis to examine the creation of trust in job interview settings found that various nonverbal cues such as gazing at a CV or job advertisement or taking up proffered gestures and incorporating them reciprocally in the discourse were resources fundamental to the development of trust (Kuśmierczyk 2014). Interestingly, these gestures and objects of eye gaze would have been inaccessible in most Zoom screen views, a modality often mentioned by participants.

Filtered out multimodal cues are relevant in relation to trust: the belief that another person will act in one's best interests when given some influence on one's affairs (Jones and Sin 2013). Trust is attained either through a record of positively evaluated historical conduct or through interactive performance (ibid). In their study of professionals' reflexive accounts of achieving trust, Jones and Sin found that accountants' self-stylization and discursive performance figured prominently in the construction of trust, but that explicit verbal 'messages were reinforced-and authenticated-by non-verbal cues' in a mutually reinforcing manner (Jones and Sin 2013, p. 162). This is in line with Goffman's theorization 
of consciously manipulable given signals of the message and the less manipulable given off non-verbal ones (Goffman 1959).

\section{Materials and Methods: Linguistic Ethnography}

The theoretical framework that informs the data collection and analysis in this study is linguistic ethnography, an approach with a strong interdisciplinary orientation (Rampton et al. 2014). An 'umbrella term, wide-ranging in its empirical scope' (Rampton 2007, p. 3), and 'an interpretive approach which studies the local and immediate actions of actors from their point of view and considers how these interactions are embedded in wider social contexts and structures' (Copland and Creese 2015, p. 13), linguistic ethnography allows for flexibility in data gathering (Copland and Creese 2015, p. 25). Calling for careful attention to discursive details-but not limited to speech—it goes beyond what is present in the text, attending to the Gumperzian edict to study 'how linguistic signs interact with social knowledge in discourse' (Gumperz 1982, p. 29).

The research was conducted in the fall of 2020 as part of a larger project about networking in elite professional services, typically inclusive of finance, law, and consulting (Rivera 2012, 2015), although the examples used in this paper are all from finance. Data came from audio- and video-recorded semi-structured interviews with 36 professionals primarily based in Hong Kong, and more than $100 \mathrm{~h}$ of field work observations. Participants were found from past research and personal acquaintances. Due to risks of embarrassment and adverse employment repercussions, several anonymizing protections were promised in informed consent forms, including redaction of names and institutions. In interviews participants were first asked if they had met anyone new for work since COVID started, which in Hong Kong was approximately February-March 2020 when cases increased from 14 to 715 . Follow-up questions typically included how networking differed from preCOVID times, how communication had changed, and how this was impacting participants business performance or their career. Data were coded by theme, including (1) professional role and the role of networking in job performance; (2) hierarchical level and length of tenure at current organization; (3) past networking practices; (4) changes in number and development of networked contacts; (5) adoption and abandonment of technologies and practices at work attributed to COVID; (6) affective stances linked to these changes; and (7) impacts on organizational and individual outcomes. This thematic organization produced recognizable patterns, one way of establishing ethnographic reliability (Fetterman 2009).

In order to make the data extracts more readable, I edited transcripts to eliminate my backchanneling and minimal responses, as well as redundancies and disfluencies from respondents. Some participant turns are not included. This is indicated by [ ... ]. When I felt that my questions or comments were important to the participant's response, I included these. Transcription conventions can be found in Appendix A.

\section{Data Analysis}

Data were selected for relevance to the different stages of the networking process, from creating contacts to cultivating them to utilizing them.

\subsection{Creating Networks}

Participants reported a quantitative decline in forming new acquaintances due to COVID. One typical example was from Scott, a partner in the Hong Kong office of a global venture capital firm, a type of private equity firm that invests in start-up companies, providing capital for growth. Seeding a company with an initial equity stake, Scott's firm expects to exit their investment when the start-up is acquired or has an initial public offering (IPO), maximizing their return on investment (ROI). Scott's primary role is to 'meet with new people to raise funds' (companies or high-net-worth individuals).

Extract 1: Expecting to meet more than 30 to 40 new people ... reduced to eight 
Scott: 1 I think I'll answer this way. I was expecting to meet more than

2 thirty to forty new people. due to COVID, that number reduced

3 to eight [... ] they do prefer- not to meet in person. even for a

4 video conference they just say- just the environment of it

5 they'd just rather delay the meeting- yeah even for Zoom.

Here Scott indicates a large decline in making of new acquaintances, from 30 to 40 'reduced to eight' (lines 2-3), which was representative of the majority of participants.

\section{Building trust}

Not only were networks in stasis, but new acquaintances largely had to be formed through computer mediated communication only, with many previously face-to-face interactions replaced with video platforms typified by Zoom, but including Google Meet, Microsoft Teams, and others. Comparisons of in-person and Zoom interactions abounded in the participant responses, often linked to trust. Relationships with new acquaintances which had not had a face-to-face component and were devoid of multi-modal cues, such as handshakes, eye gaze, and posture, were viewed as less trustworthy, as represented by Extract 2, which features Philip, a senior level professional in the private equity division of a large financial institution based in Asia that invests across the region. He is on the 'buy side', responsible for selecting companies to invest in, and indicated in the interview that he usually meets three to four hundred companies for potential investment a year, often at conferences where he meets around twenty company representatives in a day.

Extract 2: ' $I$ 'm not going to invest 20 million dollars in a start-up without sitting down.'

Philip: 1 at the end of the day, I'm not going to invest 20 million dollars

2 in a start-up without sitting down in person and taking stock

3 of the founder. shaking his hand.

Philip here indicates that he is not prepared to conclude a business relationship, 'I'm not going to invest 20 million dollars in a start-up' (lines 1-2), without the physical cues available face-to-face, exemplified by a handshake.

More evidence of the contrast perceived between embodied and disembodied copresent interactions is presented in Extracts 3 and 4. Both participants work in similar roles in institutional security sales at large financial institutions. Their jobs involve promoting security purchase and sales ideas to clients, the terms of which they negotiate with their firms' traders who execute orders. They are expected to keep abreast of financial news and market movements such as key indices and prices and to be able to weave these into convincing narratives that support their buy/sell recommendations. Part of a successful pitch is knowing various clients' particular goals and matching products accordingly: the more a salesperson knows about their client, the better able they are to match these needs. Extracts 3 and 4 show the differences between the veteran professional with established relationships and the newly hired professional, who was just beginning to form relationships when COVID arrived in Hong Kong.

\section{Extract 3: Established trust and a competitive edge}

Todd, the already established professional, earlier stated that among his clients and colleagues, there had been a $10 \%$ turnover, a lower percentage than in the past. This $10 \%$ (line 7) were new business acquaintances for him and those whom he was meeting initially through disembodied and/or remote interaction such as phone calls, Bloomberg chat, and Zoom calls.

Intvr: 1 and how about the people who you hadn't met in person yet?

Todd: 2 that was a little weird because just like when you read a book right? and

3 you read about a character and you kind of fictionalize what they look 
4 like, how they interact. what their idiosyncratic kind of mannerisms are?

5 you don't get to know them as well so there's a little bit of a lag in terms

6 of familiarity and intimacy with that person relative to the rest? [ ... ] but

7 definitely interacting with that $10 \%$ is a little more weird and not as

8 strong a relationship I would say.

Intvr: 9 how does that kind of impact the transactions that you might do, or in

10 any way? or not really?

Todd: 11 yeah no definitely. I think there are various kinds of relationship-

12 transactions. so one are just kind of the pure pricing transactions? where

13 the client wants to buy item A. they're gonna- gonna buy it at the lowest

14 price, right? so in that case, nothing really changed. but there's some

15 relationships where, they want to do something and a lot of it is based

16 on trust and, like, where they would go because A they want it to be kept

17 under wraps, or B (.) they want to do something in a very kind of-

18 particular way that they know you've done in the past and they trust you

19 to do it well. so in the first side, the pure pricing side, nothing really

20 changed because- you know whether you're doing that over Bloomberg

21 or on the phone, it's really not gonna change. but the second half, you

22 know, it's, if anything, I feel like it's kept an edge for the relationships

23 that were already strong, because they haven't an ability to develop those

24 relationships with other (.) banks? and other institutions, so we've just

25 kind of have cornered those markets, or those relationships throughout

26 COVID because we haven't had to do, because they haven't been

27 able to go elsewhere, you could say.

Todd characterizes the relationship with people not met in person as 'weird' (lines 2, 7), having less 'intimacy', 'lagg[ing] in terms of familiarity', and 'not as strong' (lines 5-7), relating it to the imagined appearance and demeanor of literary characters. He then introduces the concept of trust in lines 15 and 16 and its importance in certain types of transactions, those that require confidentiality or 'be[ing] kept under wraps' (lines 16-17) or certain expertise (lines 14-19). He clarifies that trust is earned through past historic conduct, [something] 'they know you've done in the past' (lines 18-19). Other banks that have not 'developed those relationships' (lines 23-24), that do not have that past track record, are disadvantaged. While Todd conceives of this on an institutional level, it could likewise be extended to individual actors, other salespeople, as is confirmed in the account that follows in Extract 4.

Extract 4: 'Even with Zoom, when the person's not sitting in front of you, you don't get a very strong impression.'

Calvin has recently been hired at his firm, also a global investment bank, and while not younger than Todd, he moved from the buy side to the sell side, so his clients are new to him.

Calvin: 1 but then because of this COVID, I don't get a chance to meet

2 them [potential clients] and try to talk with them in a more laid-

3 back set up like have a drink or something? so that's why I am

4 sort of stuck at the stage of only updating them [...] I mean even

5 with Zoom right because when the person's not sitting in front of

6 you you don't get a very strong impression about this person. 
7 so even with Zoom, like a client is not building a very strong

8 impression of what Calvin Chan is. you know how I am doing

9 and what's my style, right? so that's why it's very important to

10 meet clients so that they have a three dimension understanding

11 of you.

Intvr: 12 and what do you think that adds? what do you think that in-person

13 adds that's lacking in the Zoom? cause they can still see, like what

14 shirt you're wearing or they can still kind of see

Calvin: 15 yes, but then you are not like in the same room in the same

16 dimension. you don't have the feeling of being together-

17 I think that's important. so I had some difficulty? trying to break

18 into some clients- [ . . ] ] so my senior was telling me that most of

19 this is because you haven't met them [...] so they are saying that

20 when you meet someone, when they put a face to the name, it

21 really feels differently. so that's why it's not even about Zoom you

22 have to meet them, you have to touch them. so that's why you have

23 to meet them. you have to make them feel like-oh-Calvin Chan is

24 here. you know who Calvin Chan is. you have to give them a 3D

25 image of who you are. so that's why uh I think meeting them is

26 very important.

Calvin mentions throughout this extract the importance of embodied co-present interaction for really knowing someone ('you know who Calvin Chan is', line 24), and contrasts this explicitly with Zoom, a modality that leaves a weaker impression and the client is 'not building a very strong impression of what Calvin Chan is' (lines 5-8). He highlights the shared space aspect of in-person interaction: 'three dimension[ality]' (line 10) and 'the feeling of being together' (line 16), and even the importance of physical contact ('you have to touch them'). Calvin emphasizes, too, the importance of meeting in a different setting from work, indicating that it should be laid-back (lines 2-3) like 'getting a drink', an example used by many in this study and the topic of a later section (Section 4.2).

\section{Authorization through a trusted entity}

While salespeople at global investment banks could rely on their institution for some introductions that would be somehow digitally mediated, professionals at smaller institutions have less institutional power on which they can rely. Many participants indicated the importance of introductions from a third party, such as investors at other firms and contacts at larger institutions, as well as shared affiliations such as university alumni or professional association membership. The use of these bridging connections as substitutes for face-to-face evaluation was frequently mentioned as a compensating strategy for the realization of business goals. The trusted entity's evaluation provides the confident expectation of integrity, ability, and performance (grounded in historical past observation). This was most succinctly relayed by Miles, director at a private equity firm with a niche focus. In his work, he assembles complex consortiums from different entities to jointly execute high-value capital-intensive projects and connects with potential investors seeking partnerships or joint activities in Asia-Pacific.

\section{Extract 5: Trusted bridges}

Miles: 1 so I've done new deals- I've done deals with people I didn't

2 know- but I've only done new deals with new people I didn't

3 know if there was a bridge made by someone else who was 
4 somehow able to compensate for the lack of face-to-face. what

5 happens-and I do the same with some people, I hire. [ . . ] I see

6 also with others you need some mechanism, to compensate for

7 the fact that you cannot have that face-to-face discussion.

8 and what I've seen is it's very much done. through intermediaries

9 that you trust.

Miles signals that he has only completed transactions with new people if there was a 'bridge' from 'someone else' who 'could compensate for the lack of face-to-face' interaction (lines 3-4). He mentions the explicit link between the COVID-imposed absence of face-to-face interactions (lines 7-8) and the need for a compensatory mechanism for warranting of trustworthiness (lines 6-8); and that this mechanism is a recommendation by a trusted intermediary (line 9). Extrapolating from Miles and the reports of a majority of the participants in this study, people with established track records, who have maintained amiable relations with past collaborators, are part of well-connected networks, and are comfortable asking for recommendations, clearly stand to benefit in the COVID economy, while those who do not, stand to be at a disadvantage in terms of finding new clients, collaborators, employers, and employees.

\subsection{Cultivating Networks}

\section{'Getting a drink at a bar'}

Creating a network contact moves a relationship along the continuum from stranger to acquaintance. Moving from acquaintance to trusted partner means cultivating the relationship through further interaction, the most typical activity for doing so represented by participants as 'getting a drink together'. The topics and style of work-related drinks may differ somewhat from purely social interactions, with topics that are 'personal but not private or "intimate"' (Svennevig 1999, p. 103), such as travel destinations (Extract 6, line 14), yet the two genres share many similarities, imbuing business relationships with more of a social tinge. Many in this study communicated strongly-held beliefs that these types of activities that had functioned face-to-face could neither be conducted over Zoom, nor had suitable other replacements. The first example is from Calvin, the salesperson in finance introduced in Extract 4.

\section{Extract 6: Drinks: 'that's how you build bondings'}

Calvin: 1 oh because like in Zoom call like imagine if you do a Zoom

2 call with your client, right? it's usually you have a purpose-

3 like it's let's discuss the market- discuss the China rates or

4 whatever- you have a particular purpose. but if you go for a

5 drink with a client- of course you can mention a little bit about

6 trades you can mention a little about market- but also you don't

7 have like a fixed agenda- for the drink, right? so you chit-chat,

8 you talk about a different thing, and then that's how you build

9 bondings right? but for a Zoom call, you don't do like a happy

10 hour Zoom call with your client right? [ . . . ] I mean you can try to

11 do a little bit of, small spee:ch, like, 'how you're doing? ' you try to

12 get to know him a little bit more- but it's not like you go down to

13 a bar, and then you sit down, and then of course you talk about

14 market, but you also talk about, where did you travel before

15 etcetera. you don't do that on Zoom calls-

Intvr: 16 why do you think not though? 'cause you could- 'cause you 
17 do, do that with like friends who are living somewhere else.

Calvin: 18 yes, but Zoom calls are all during working hours, right? so

19 people would be like- okay, 'cause it's working hour, we're busy,

20 so let's just talk about market- talk about work, and then the

21 week is over and then we move on. so there's not much casual

22 conversation during a Zoom call, of course you probably greet

23 each other, and ask what did you do over the weekend, etcetera

24 but you just stop there.

Calvin argues that Zoom work calls have a 'purpose' (lines 2, 4), a central situational focus that is a key feature of formality (Irvine 1979), whereas drinks talk is more openended and wide-ranging, 'you don't have a fixed agenda ... you chit-chat, you talk about a different thing' (lines 6-9) and 'you also talk about where did you travel before, etcetera' (lines 14-15). When I, as the interviewer, suggest that there is nothing inherent in a video call to preclude social talk (lines 16-17), Calvin indicates that the temporal aspect of the workday, while allowing for some abbreviated social talk (lines 10-12), makes it inappropriate for extensive social talk. The work of professionals in sales and on trading desks is usually intense. Moreover, they are bound to the computer during the day, preventing any improvised, meandering social exchanges during that time, and although there is nothing to preclude after-hours socializing over Zoom, it does not occur. This could speak more to the way that professionals have been socialized into using Zoom and the strong connections they have with Zoom being for transactional business than constraints in the platform itself. The feeling that grabbing drinks together over Zoom is 'weird' and 'just not done', could therefore very well be a conception about norms for the professional acquaintancing activity type and not wanting to transgress those norms and be seen as socially inept. Although popular media accounts document friends or co-workers having Zoom happy hours or coffee breaks on video platforms, none of the interviewees talked of any substitute for 'grabbing a drink/coffee' with a new acquaintance being replaced with a video platform equivalent.

Another participant, Aiden, who also works in sales and trading at a large global financial institution, typically went out for drinks or dinner with clients two nights a week and colleagues once a week. He saw this as an integral part of the job. When asked why Zoom drinks could be done but were not, Aiden replied:

\section{Extract 7: 'Grabbing drinks: I associate that with fun and friends.'}

Intvr: 1 given that on Zoom or Facetime we talk to people all the time-

2 socially, why wouldn't you do that after work with someone

3 new?

Aiden: 4 grabbing drinks is something I do with friends on the

5 weekends- and have been doing since school, so I associate

6 that with fun and with friends. but a drink on a Zoom call?

7 no! the rhythm is off, you miss how they move, lots of body

8 language, it's just not fun.

Intvr: 9 ok, I get that it's not as good as in person, but the same for

10 business meetings and you still do those. I would think

11 something is better than nothing.

Aiden: 12 no. there's also the feeling I'm still at work, in the same

13 office or in front of the same computer-I can't relax. it's not

14 fun. grabbing a drink is at a bar- or a restaurant, there's a

15 buzz, people are unwinding, laughing, it's comfortable, 
16 no bright lights. it's a completely different atmosphere.

In lines 4 to 5 , Aiden's interpretation of getting drinks as 'something I do with friends on the weekends' shows a link to a more informal frame of mind and footing for the relationship. The evaluation of in-person drinks as 'fun' and Zoom drinks as 'not fun' (lines 5-7) reflects varying subjectively felt evaluations of pleasure, an attitude present throughout the data and a reminder that enjoyment is a consideration in whether actors pursue or avoid an activity. Getting drinks also involves a change in setting from 'the same office or in front of the same computer' (lines 12-13) to a buzzy bar or restaurant, with accompanying sensorial elements, such as the taste of alcohol and food, the sound of surrounding laughter, the aura of softer lighting, that are related to the activity of 'getting to know each other at a bar' that are absent in a Zoom call. Some of these dimensions would seem to be somewhat manipulatable through changes in lighting, camera position, or background, yet no one in this study seemed to have been involved in any such effort.

Informality, signaling of positive personal affect (in extending the invitation), embodied co-presence, a distinctly different location from where business is conducted, and an accompanying sensatory environment are the aspects associated with 'getting a drink at a bar' by the participants in the study. They are viewed as conducive to mutual personal disclosure and a somewhat more socially tinged relationship, which are in turn viewed as conditions for deepening a business relationship.

\section{Multiparty events}

The second type of activity that was repeatedly mentioned for cultivating business acquaintances and was also deemed irreproducible by participants, was the networking event. Attempts have been made to replicate the social serendipity that professionals might have encountered at coffee breaks of conferences, at alumni or charity gatherings, or even in their organizations, at happy hours when introduced to someone new by a common acquaintance, through video platforms. The evaluations of these online events by participants focused on limitations, negative comparisons to pre-COVID in-person events, and feelings of obligation to participate.

I observed and took field notes of several Zoom recreations of social professional events such as team bonding activities and large divisional parties within participants' organizations, for example, cooking classes, painting classes, or wine tastings. The necessary materials (paints, cooking ingredients, wine) were shipped to or assembled at each individual home and then the group (ranging in size from 8 to more than 100 people) would do the activity synchronously, with prompts from a leader or instructor. These events were variously evaluated, but all participants indicated that they saw them as being less enjoyable than in-person interaction and less effective for enabling true person-to-person interaction. One participant from sales and trading at a large global investment bank attended a Zoom cross-divisional annual company wine tasting event with a sommelier leading $100+$ people. He described it as follows:

\section{Extract 8: Networking on Zoom: wine tasting}

Kit: 1 let me put it this way. this was the year end party for our

2 division. I've been to five of these. the first was karaoke,

3 the second was an escape room, the next was Mexican food,

4 and the other was something I forget. and then this. this

5 was by far the worst.

Intvr: 6 why?

Kit: 7 so at a party I'd head for the people I like first and talk with

8 them. at dinner, I'd be sitting by different people- there might

9 be three-four conversations going. I guess there are break

10 rooms or something on Zoom, but we haven't used them, 
11 so I can't say. and here it's just one person talking, like a yoga

12 class. a few senior people making comments, some people

13 trying to be funny, but it just wasn't that fun.

Intvr: 14 did you meet anyone new?

Kit: 15 no

Intvr: 16 have you been to any online networking events like you used

17 to go to for your college, for finance professionals,

18 nonprofits

Kit: 19 no

In explaining why he thought the wine tasting event compared negatively to the others evaluation (line 5 'by far the worst'), Kit first indicates his appreciation of choice and agency over whom to interact with in face-to-face events, by 'head(ing) for the people I like first' (line 7). He also mentions that the format of the online event meant that one person spoke the majority of the time, with most people silently listening and very occasionally a few commenting, which resulted in a lack of one-on-one or small group interaction. These observations hearken back to the 'traversability' affordance of serendipitous events discussed earlier (Section 2.2) and include 'explorability' and 'slowability' (Björneborn 2017), two affordances that are not hallmarks of Zoom. Exploring in these events would translate to agency in selecting conversational partners and topics. Slowability is theorized as the ability to slow down and linger in one location, which to accomplish would require more individual agency over the duration of interactions, which is lacking in an imposed ten-minute time frame of a breakout room where co-participants, moreover, are assigned by the hosts, often randomly. Kit's responses to the final two questions (lines 14-19) corroborated my observations and other participants' accounts that online events during COVID, as constructed in these accounts, were not suitable for cultivating and deepening relationships.

It may be concluded that the dyadic and multiparty relationship building events described above were portrayed as poor shadows of their in-person manifestations when reproduced in CMC. Beliefs of what are acceptable parameters for 'natural', 'normal', not 'weird' (often dyadic) acquaintance building environments and modalities for professional contacts were seen to demand co-presence and to dictate certain locations such as a bar, café, or restaurant. Likewise, the fact that this type of activity usually occurs after work hours at the end of the day, when Zoom fatigue sets in, could contribute to participants' lack of appreciation.

Meanwhile, networking activities, such as the Zoom wine tasting in Extract 8, which, when conducted in person, feature frequent reconfigurations of interactants enacted through movement across space, are truly irreproducible in most commonly used video platforms, as currently configured. Agency over movement, time, and interactants is missing. The modified lecture or lesson-like format neglects the social interactional aspects that are most highly prized for being 'fun' and 'enjoyable'.

\subsection{Utilizing Networks}

In addition to impacting the creation and cultivation of relationships, COVID-driven changes also affected the utilization of relationships. Interestingly, here the changes were also seen to provide affordances beyond the constraining effects described by participants in raising funds from new investors (Extract 1), establishing new collaborations (Extracts 2 and 5), and securing certain types of sales (Extracts 3 and 4). Participants mentioned two benefits: one relates to more 'objective' quantitative judgements with less influence of personal factors (Extract 9) and the other to an equalizing force in relationships for people working in locations more geographically remote to the corporate power center, such as headquarters (Extract 10). 


\section{Extract 9: Ability to talk with numbers}

Roland works in a buyout firm, a type of private equity that focuses on buying undervalued, underperforming businesses, improving their margins, and selling them at a profit. Identifying buying opportunities can be a large thrust of their operations and they rely on 'their extensive networks of business and financial connections, including potential bidding partners, to find new deals' (Barber and Goold 2007, p. 60).

Roland: 1 so yeah. I think it's been helpful to me it's slightly unusual,

2 but like the Zoom culture has been helpful to me in broadening

3 my ability to meet people and talk with numbers. I feel like a

4 deep-it's, like, way more shallow now.

Roland differed from other participants in relaying that he had concluded business with people he met after the start of COVID and positively evaluated the disembodied, cues filtered-out Zoom interaction ('helpful to me' line 2). He believes that a focus on numbers is an asset (line 2-3). It is unclear how he conceives of the relationship between numbers (assumed to be measures of profitability, asset valuation, etc.), trust, and embodied co-present cues: it may be that personal feelings influenced by these cues are better disregarded, or it may be that the numbers should be all that is considered in a decision. However, he clearly does not view co-present cues as necessary for making high-stakes investment decisions. Instead, he prefers relying solely on numbers, on a more systemdriven process, similar to computer algorithms. This is a view of cues as distractions that trick us into unwise evaluations.

\section{Equalizing force}

Another benefit of Zoom interactions was mentioned by a very senior finance professional who had several weekly meetings, comprised of the highest level of executives, where 8 of the 10 people present were in a conference room in London, one from Hong Kong and one from New York. With the arrival of COVID, everyone participated on Zoom. Dan describes pre-COVID meetings as follows:

\section{Extract 10: 'We're all on equal ground'}

Dan: 1 there's the side chats that you're not a part of, right? it's like,

2 "come o:n, stop the chatting, let's get on with the meeting", right?

3 so that's gone away because we're all on equal ground, right

4 now. so we're pre-meeting you know as people Zoom in to start,

5 there's some "hey" one off conversations and then it all of a sudden

6 stops when we're ready to go. so it's much more of an equalizer

7 right now.[ ... ] it puts people more on equal footing. it sort of

8 depends on who's running the meeting, but typically the

9 person running the meeting, whoever that might be has his or

10 her natural biases and might go to two or three go-to people

11 all the time and the body language is right there and you can

12 see, and so he or she would stop and call on somebody. but

13 now that's a lot less so now. you see a little bit of that now

14 but not as much so I think, yeah, it's more on equal footing.

Dan indicates the exclusionary aspect of previous mixed face-to-face and video meetings with 'side chats that you're not a part of' and 'chatting' (lines 1-2) contrasted to the current situation where it is more 'equal ground' (line 3), 'equal footing' (lines 7, 14). Previously, 'natural biases' and reactions to 'body language' (lines 9-11) would preference those experiencing the meeting face-to-face. As someone not physically present at these 
high-stakes face-to-face meetings, Dan implies he was at a disadvantage. In organizations with some employees participating in decision-making virtually over Zoom, such as in Hong Kong in this example, and some employees participating in decision making in person, such as at headquarters in London, not all employees are on equal footing in terms of being heard, recognized, and connected to.

In Extract 10 we see a more 'equalizing' outcome for people geographically remote from the center of power, in this case the headquarters in London. Even though Dan and his colleagues in New York have had some in-person interaction with their colleagues in London and thus been warranted, they have still encountered adverse effects of being peripheralized, by not being physically co-present in meetings. They perceive discrepancies of interaction modalities as overwhelmingly favoring those who are present in person rather than remotely in terms of speaker rights.

\section{Results of the Study}

In times of COVID, networking practices have changed profoundly for business people in Hong Kong. Interactions that in the past were embodied and co-present have now become mediated through technology, including the addition of video platforms, represented by Zoom. They also have decreased in number and perceived quality. For most participants, the creation of new contacts has markedly decreased as socially serendipitous events as configured in the past have shown to be irreproducible (Extracts 1,6,7,8). For those involved in soliciting and allocating capital (Extracts 1,2,5), this decrease in meeting new acquaintances has led to a deterioration of outcomes (with one exception: see Extract 9). For cultivating existing contacts, the absence of socially tinged, face-to-face encounters such as getting drinks at a bar and sharing personal information (Extracts 3,4,6,7) has proven to be an obstacle, privileging those who established relationships in person before the advent of COVID and penalizing those who are attempting to build their relationships during COVID through CMC. Likewise, for utilizing networked connections, in the absence of embodied co-present interaction and its accompanying cues, most participants are finding themselves less successful at achieving professional goals (Extracts 2,3,4,5).

For each phase of networking (creation, cultivation, and utilization) some degree of evaluation, validation, and trusting has to occur. For most of the participants, there is a hierarchy of modalities for evaluating potential professional contacts. Except for Roland (Extract 9), embodied co-presence is held to be the gold standard: not only preferable, but essential. In order to establish the necessary trust for making business decisions, from small incremental ones to high-stakes investments or hiring decisions, embodied co-presence is viewed as necessary to properly validate initial impressions, evaluate character, or assess ability.

The participants in the study mentioned specific nonverbal trust-warranting cues that they associate with trust, such as 'handshakes', 'eye contact' and 'where they look', 'mannerisms', 'gestures', 'posture', 'how they carry themselves', 'a certain presence', 'enthusiasm', 'the physical part', 'how they engage', and 'three dimension[ality]'.These trust-imbuing cues are believed to be essential and to be missing in remote but embodied interaction. All but one participant stated that without them, they experience difficulty in forming accurate impressions that would generate sufficient trust to commit economic resources to a new endeavor. For them, disembodied language (i.e., mediated through chat platforms or phone calls) or even embodied but not co-present language (i.e., mediated by Zoom) is inferior for decisions of trust as it does not provide reliable signals as to character or ability.

This can be seen as evidence that the early 'cues filtered out' view of CMC still holds true for many and results in tangible impact for nearly all of the participants in this study. The two accounts of the salespeople in nearly identical roles in nearly identical organizations, established Todd and newly-hired Calvin, highlight the different personal consequences of possessing in-person validation for occupational goals for individuals. Both are part of large, profitable organizations, affiliation with which grants a certain level of institutional trust, but individual sales that accrue to and are tracked for individual 
performance hinge on individual trust present (or absent) in relationships with other individuals. This circles back to the fundamental question of how trust is warranted and discursively constructed posed by Candlin and Crichton (2013), an important point as warranting is a precondition for concluding business deals or achieving other outcomes that are the goals to which networking ultimately orients.

However, for finance in Hong Kong meeting in person and chatting over drinks at a bar is not the complete answer. There remains a chain of validating events including school admissions, recommendation letters, resumes, and interviews that lead to affiliation with an organization. There are interactions over Bloomberg chat and the phone, where demeanor and information provided are evaluated, and perhaps reports from others. Still, without the linchpin of in-person interaction, trust is not fully bestowed, and the type of in-person interaction preferred for this is some socially tinged meeting typified by getting drinks at a bar, where there is mutual disclosure of personal information, similar to acquaintancing interactions reported in other studies, e.g., students in Australia, Sweden, the U.S., and professionals in Sweden and Japan, (Maynard and Zimmerman 1984; Svennevig 1999; Usami 2006; Silverstein 2004; Haugh and Carbaugh 2015).

It has been said that CMC can achieve similar positive outcomes to in-person interaction given additional time, and given projected future interaction (Walther 1994). In contexts such as online classes, that anticipated future interaction can be guaranteed at least through the semester and often even longer. This differs from business contexts where there is no guaranteed future interaction. There is the possibility to reject the initial acquaintance, the deeper acquaintance, the collaboration, or the transaction, often in favor of existing acquaintances who have warranted trust through embodied co-present cues that validated initial appraisals. While surely there are other ways to warrant trust, as mentioned earlier, such as historical performance and certifying qualifications, for participants in this study the cues encountered in face-to-face interaction were nearly always necessary. The only exception that surfaced in the data was the figure of the trusted bridge, who assumedly had performed this in-person validation in some other place, at some other time.

\section{Wider Issues}

Although the current configurations of platforms such as Zoom that were most used by participants in this study were deemed unsatisfactory, platforms that incorporate at least one feature of serendipity-movement and selection of interactants, conceived of as 'traversability' (Björneborn 2017)—were viewed positively (Russell 2020). These were not mentioned in the data, but several such platforms exist, including Cuppa, an online coffee shop, and High Fidelity, from the creator of Second Life, as replacements for pub visits or parties (Russell 2020). High Fidelity uses background screens associated with social events such as living rooms in homes with participants moving around, not as avatars, but as dots on a bird's-eye view of a house, and sound coming in 3D spatialized audio so that conversations are only perceptible when dots are in proximity (Russell 2020). The visual sensorability (Björneborn 2017) aspect of serendipity has been somewhat sacrificed in this model, but the audio approaches face-to-face perceptions. Of the frequently-used workplace video platforms, Microsoft Teams has incorporated some of this agency into its Together feature. Whether these new platforms that have been positively reviewed by people who are on Second Life or whether the new features such as Together would be similarly accepted in the business world as replacements for networking remains to be seen.

These are early days of the forced separation of bodies. Humans have always responded to new circumstances and adapted to new technologies when viewed over a longer time span, such as, e.g., moving to typewriting from handwriting, despite perceived drawbacks. With COVID, adoption of new modalities has been temporally compressed; it has been imposed, there was no option. Perhaps imposition of the new modalities, and dissatisfactions with filtered-out cues that they entail, means that as the pandemic ebbs, the ubiquity of new modalities such as Zoom will, too. Or perhaps the fast and 
wide adoption of new modalities and new organizational conceptions of work life, such as work-from-home, will remain, resulting in CMC and Zoom becoming the modalities of choice, with embodied co-present interactions declining dramatically. Or perhaps the future is more textured with multiple effects as suggested by Extracts 9 and 10, with some networks prospering, others stagnating, and yet others languishing.

Funding: This research received no external funding.

Institutional Review Board Statement: The study was conducted according to the guidelines of, and approved by the Human Research Ethics Committee of The University of Hong Kong (EA200191) 24 February 2021.

Informed Consent Statement: Informed consent was obtained from all subjects involved in the study.

Data Availability Statement: Due to privacy concerns and anonymity promised in the informed consent agreements, data cannot be shared.

Acknowledgments: I would like to thank Adam Jaworski, the three anonymous reviewers, and the editors Anne Bannink and Jet van Dam van Isselt for their feedback and suggestions. All shortcomings are solely my own.

Conflicts of Interest: The author declares no conflict of interest.

\section{Appendix A Transcription Conventions}

Based on the 'Jefferson System' as outlined in Atkinson et al. (1984), as well as Gumperz and Berenz (1993).

$\begin{array}{cl}\text { Symbol } & \text { Significance } \\ \text { sentence-final falling intonation } \\ \text { slight rise in tone, more to come } \\ ! & \text { animated tone, includes but not only exclamations } \\ ? & \text { final rise, as in a question, but not limited to questions } \\ - & \text { sharp cut off } \\ \text { underline } & \text { dialogue or represented speech/thoughts } \\ {[\ldots]} & \text { emphasis } \\ & \text { some speech from the original is omitted }\end{array}$

\section{References}

Adami, Elisabetta, Najma Al Zidjaly, Germán Canale, Emilia Djonov, Maryam S. Ghiasian, Clarice Gualberto, Styliani Karatza, Fei Victor Lim, Ana Pedrazzini, Jesse Pirini, and et al. 2020. PanMeMic manifesto: Making meaning in the COVID-19 pandemic and the future of social interaction. Urban Language $\mathcal{E}$ Literacies 273: 20.

Adler, Paul S., and Seok-Woo Kwon. 2002. Social capital: Prospects for a new concept. Academy of Management Review 27: 17-40. [CrossRef]

Atkinson, J. Maxwell, John Heritage, and Keith Oatley. 1984. Structures of Social Action. Cambridge: Cambridge University Press.

Barber, Felix, and Michael Goold. 2007. The strategic secret of private equity. Harvard Business Review 85: 53. [CrossRef]

Batistic, Saša, and Alex Tymon. 2017. Networking behaviour, graduate employability: A social capital perspective. Education+ Training 59: 374-88. [CrossRef]

Björneborn, Lennart. 2017. Three key affordances for serendipity: Toward a framework connecting environmental and personal factors in serendipitous encounters. Journal of Documentation 73: 1053-81. [CrossRef]

Blakely, Lindsay. 2020. Fear of Returning to Work: When You're Ready But Your Employees Are Not. Inc. Available online: https:/ / www.inc.com/lindsay-blakely/post-COVID-leadership-employees-fear-return-work.html (accessed on 9 March 2021).

Bourdieu, Pierre. 1977. The economics of linguistic exchanges. Social Science Information 16: 645-68. [CrossRef]

Bourdieu, Pierre. 1986. The forms of capital. In Handbook of Theory and Research for the Sociology of Education. Edited by John Richardson. Westport: Greenwood, pp. 241-58.

Bray, Chad. 2020. HSBC, Standard Chartered reinstate work-from-home measures as 'third wave' of coronavirus hits Hong Kong. South China Morning Post. Available online: https:/ / www.scmp.com/business/banking-finance/article/3093304/hsbc-standardchartered-reinstate-work-home-measures-third (accessed on 9 March 2021).

Bucholtz, Mary, and Kira Hall. 2016. Embodied sociolinguistics. In Sociolinguistics: Theoretical Debates. Edited by Nikolas Coupland. Cambridge: Cambridge University Press, pp. 173-97. 
Candlin, Christopher N., and Jonathon Crichton, eds. 2013. Discourses of Trust. London: Palgrave Macmillan UK. [CrossRef] Copland, Fiona, and Angela Creese. 2015. Linguistic Ethnography: Collecting, Analysing and Presenting Data. London: Sage.

Culnan, Mary, and M. Lynne Markus. 1987. Information technologies. In Handbook of Organizational Computing: An Interdisciplinary Perspective. Edited by Frederic Jablin, Linda Putnam, Karlene Roberts and Lyman Porter. London: Sage.

Dahlheim, Mayannah N. 2016. The Intimacy of Writing_Lost in a Digital Age? In Materiality and Popular Culture: The Popular Life of Things. Edited by Anna Malinowska and Karolina Lebek. London: Routledge, pp. 77-87.

Ellison, Nicole, Rebecca Heino, and Jennifer Gibbs. 2006. Managing impressions online: Self-presentation processes in the online dating environment. Journal of Computer-Mediated Communication 11: 415-41. [CrossRef]

Fetterman, David. M. 2009. Ethnography: Step-by-Step. London: Sage Publications, vol. 17.

Gibson, Carter, Jay H. Hardy III, and M. Ronald Buckley. 2014. Understanding the role of networking in organizations. Career Development International 19: 146-61. [CrossRef]

Goffman, Erving. 1959. The Presentation of Self in Everyday Life. Garden City: Doubleday.

Greve, Joan. 2020. US state governors impose tighter restrictions to slow coronavirus spread. The Guardian. Available online: https: //www.theguardian.com/us-news/2020/mar/20/new-york-coronavirus-andrew-cuomo-non-essential-workers-businesses (accessed on 9 March 2021).

Gumperz, John J. 1982. Discourse Strategies. Cambridge: Cambridge University Press, vol. 1.

Gumperz, John J., and Norine Berenz. 1993. Transcribing conversational exchanges. In Talking Data: Transcription and Coding in Discourse Research. Edited by Jane A. Edwards and Martin D. Lampert. New York: Psychology Press, pp. 91-122.

Haugh, Michael, and Donal Carbaugh. 2015. Self-disclosure in initial interactions amongst speakers of American and Australian English. Multilingua 34: 461-93. [CrossRef]

Hong Kong Monetary Authority. 2021. Competitive International Financial Platform; Hong Kong: Hong Kong Monetary Authority. Available online: https / / www.hkma.gov.hk/eng/key-functions/international-financial-centre/hong-kong-as-an-internationalfinancial-centre/competitive-international-financial-platform/ (accessed on 21 March 2021).

Irvine, Judith T. 1979. Formality and informality in communicative events. American Anthropologist 81: 773-90. [CrossRef]

Jang, In Chull, and Lee Jin Choi. 2020. Staying connected during COVID-19: The social and communicative role of an ethnic online community of Chinese international students in South Korea. Multilingua 39: 541-52. [CrossRef]

Jones, Alan, and Samantha Sin. 2013. Achieving professional trustworthiness: Communicative expertise and identity work in professional accounting practice. In Discourses of Trust. Edited by Christopher N Candlin and Jonathon Crichton. Basingstoke: Palgrave Macmillan UK, pp. 151-66. [CrossRef]

Kuśmierczyk, Ewa. 2014. Trust in action: Building trust through embodied negotiation of mutual understanding in job interviews. In Trust and Discourse: Organizational Perspectives. Edited by Katja Pelsmaekers, Geert Jacobs and Craig Rollo. Discourse approaches to politics, society, and culture; v. 56. Amsterdam: John Benjamins Publishing Company, pp. 11-44.

Levinson, Stephen C. 1979. Activity types and language. Linguistics 17: 365-99. [CrossRef]

Lin, Nan. 1999. Social networks and status attainment. Annual Review of Sociology 25: 467-87. [CrossRef]

Maynard, Douglas W., and Don H. Zimmerman. 1984. Topical Talk, Ritual and the Social Organization of Relationships. Social Psychology Quarterly 47: 301. [CrossRef]

Morgan, Vicky L., and Cheri A. Toledo. 2006. Online Feedback and Student Perceptions. Journal of Interactive Online Learning 5: 333-40.

Noonan, Laura, Primrose Riordan, and Philip Stafford. 2020. Banking: The great return to the office. Financial Times. Available online: https: / / www.ft.com/content/0c32560c-fdcf-4a76-8b07-223825bc5b0b (accessed on 9 March 2021).

Olshannikova, Ekaterina, Thomas Olsson, Jukka Huhtamäki, Susanna Paasovaara, and Hannu Kärkkäinen. 2020. From Chance to Serendipity: Knowledge Workers' Experiences of Serendipitous Social Encounters. Advances in Human-Computer Interaction 2020: 1-18. [CrossRef]

Piller, Ingrid, Jie Zhang, and Jia Li. 2020. Linguistic diversity in a time of crisis: Language challenges of the COVID-19 pandemic. Multilingua 39: 503-15. [CrossRef]

Rampton, Ben. 2007. The Micro-Analysis of Interactional Discourse in Linguistic Ethnography: An Illustration Focused on the Job Interview'. Oxford: ESRC Researcher Development Initiative, Ethnography, Language and Communication.

Rampton, Ben, Janet Maybin, and Celia Roberts. 2014. Methodological foundations in linguistic ethnography. Tilburg's Paper in Cultural Studies, Paper 102. Available online: https:/ / research.tilburguniversity.edu/en/publications/methodological-foundations-inlinguistic-ethnography (accessed on 12 October 2020).

Richardson, Jennifer C., Yukiko Maeda, Jing Lv, and Secil Caskurlu. 2017. Social presence in relation to students' satisfaction and learning in the online environment: A meta-analysis. Computers in Human Behavior 71: 402-17. [CrossRef]

Rivera, Lauren A. 2012. Hiring as Cultural Matching: The Case of Elite Professional Service Firms. American Sociological Review 77: 999-1022. [CrossRef]

Rivera, Lauren A. 2015. Pedigree: How Elite Students Get Elite Jobs. Princeton: Princeton University Press.

Russell, Anna. 2020. Zoom fatigue and the new ways to party. New Yorker. Available online: https://www.newyorker.com/culture/ culture-desk/zoom-fatigue-and-the-new-ways-to-party (accessed on 22 February 2021).

Silverstein, Michael. 2004. "Cultural" Concepts and the Language-Culture Nexus. Current Anthropology 45: 621-52. [CrossRef]

Svennevig, Jan. 1999. Getting Acquainted in Conversation: A Study of Initial Interactions. Amsterdam: John Benjamins Publishing, vol. 64.

Tannen, Deborah. 1984. Conversational Style: Analyzing Talk among Friends. Oxford: Oxford University Press. 
Usami, Mayumi. 2006. Discourse politeness in Japanese conversation: Some implications for a universal theory of politeness. In Readings in Second Language Pedagogy and Second Language Acquisition: In Japanese Context. Tokyo: Hitsuji Shobo, pp. $19-41$.

Verlaine, Julia-Ambra. 2020. Deutsche Bank tells U.S. staff they can wait until mid-2021 to return to office. Wall Street Journal. Available online: https:/ / www.wsj.com/articles/deutsche-bank-to-tell-u-s-staff-they-can-wait-until-mid-2021-to-return-to-office-1160 0285400 (accessed on 9 March 2021).

Walther, Joseph B. 1994. Anticipated ongoing interaction versus channel effects on relational communication in computer-mediated interaction. Human Communication Research 20: 473-501. [CrossRef]

Walther, Joseph B., Jeffrey F. Anderson, and David W. Park. 1994. Interpersonal effects in computer-mediated interaction: A metaanalysis of social and anti-social communication. Communication Research 21: 460-87. [CrossRef]

Walther, Joseph B., and Eun-Ju Lee. 2014. Computer-mediated Communication. In Interpersonal Communication. Edited by Charles Berger. Berlin: De Gruyter Mouton, pp. 541-64.

Wardle, Michael, and Michael Mainelli. 2021. The Global Financial Centres Index. Long Finance and Financial Centre Futures, No. 29. p. 64. Available online: https://www.longfinance.net/programmes/financial-centre-futures/global-financial-centres-index/ (accessed on 9 March 2021).

Wolff, Hans-Georg, and Klaus Moser. 2009. Effects of networking on career success: A longitudinal study. Journal of Applied Psychology 94: 196-206. [CrossRef] [PubMed] 